\title{
MASDAR, LA CIUDAD DEL FUTURO ${ }^{1}$ \\ Entre la sustentabilidad y la espectacularidad.
}

\author{
Daiana Zamler
}

\section{Resumen}

La construcción de una ciudad ex-novo pone de manifiesto múltiples cuestionamientos sobre el significado de la ciudad en sí. Que la ciudad ex-novo sea la primera ciudad con cero emisiones de carbono en el mundo, la más sustentable de todas las ciudades, nos hace reflexionar acerca de los conceptos de ciudad y de sustentabilidad. El paradigma de Masdar City nos deja heterogéneos y valiosos aprendizajes.

Palabras clave: Ciudad, sustentabilidad, Masdar, futurista, energía, megaproyecto.

Keywords: City, sustainability, Masdar, futuristic, energy, megaproject. 
I a evolución demográfica del planeta pone a la ciudad en el centro de la acción del siglo XXI. Hoy más del 50 por ciento de la población mundial, - o que se traduce en más de 3.500 millones de personas, vive en espacios urbanizados. Esta proporción llegará al 60 por ciento en 2020. Mientras que se estima que en el año 2030, alcanzará prácticamente los 5.000 millones de personas, lo que representará al menos el $75 \%$ de la población mundial (Hurtado, 2013). Para satisfacer sus crecientes necesidades, las ciudades extraen energía del mundo que las rodea, proporcionando beneficios a escala local pero generando negativas repercusiones en el ambiente. Dado que en las próximas décadas la inmensa mayoría del incremento del suministro energético estará dedicado a cubrir el aumento de la demanda en las ciudades, éstas jugarán un papel más activo en la planificación y diseño de su propio futuro energético (Rivas Ecópolis, 2008).

En el año 2006 se dio inicio a un novedoso proyecto ubicado en los Emiratos Árabes Unidos: Masdar City, la nueva ciudad diseñada por los arquitectos británicos Foster \& Partners, busca ser la fuente de ensayos de la ciudad futura, la primera en el mundo $100 \%$ ecológica (cero emisiones de $\mathrm{CO}_{2^{\prime}}$ cero residuos y $100 \%$ energía renovable), a 17 kilómetros de Abu Dhabi en el corazón del páramo arábigo, se edifica con un costo estimado de 22.000 millones de dólares (Fundación Expoterra, 2012). El objetivo es analizar el revolucionario desarrollo urbano en búsqueda de comprender sus procesos y objetivos en pos de ser la primera ciudad $100 \%$ sustentable del mundo. Se indaga respecto de los aprendizajes que nos deja Masdar, y cuál es el estado actual del megaproyecto.

\section{Diseño y particularidades de la ciudad del futuro}

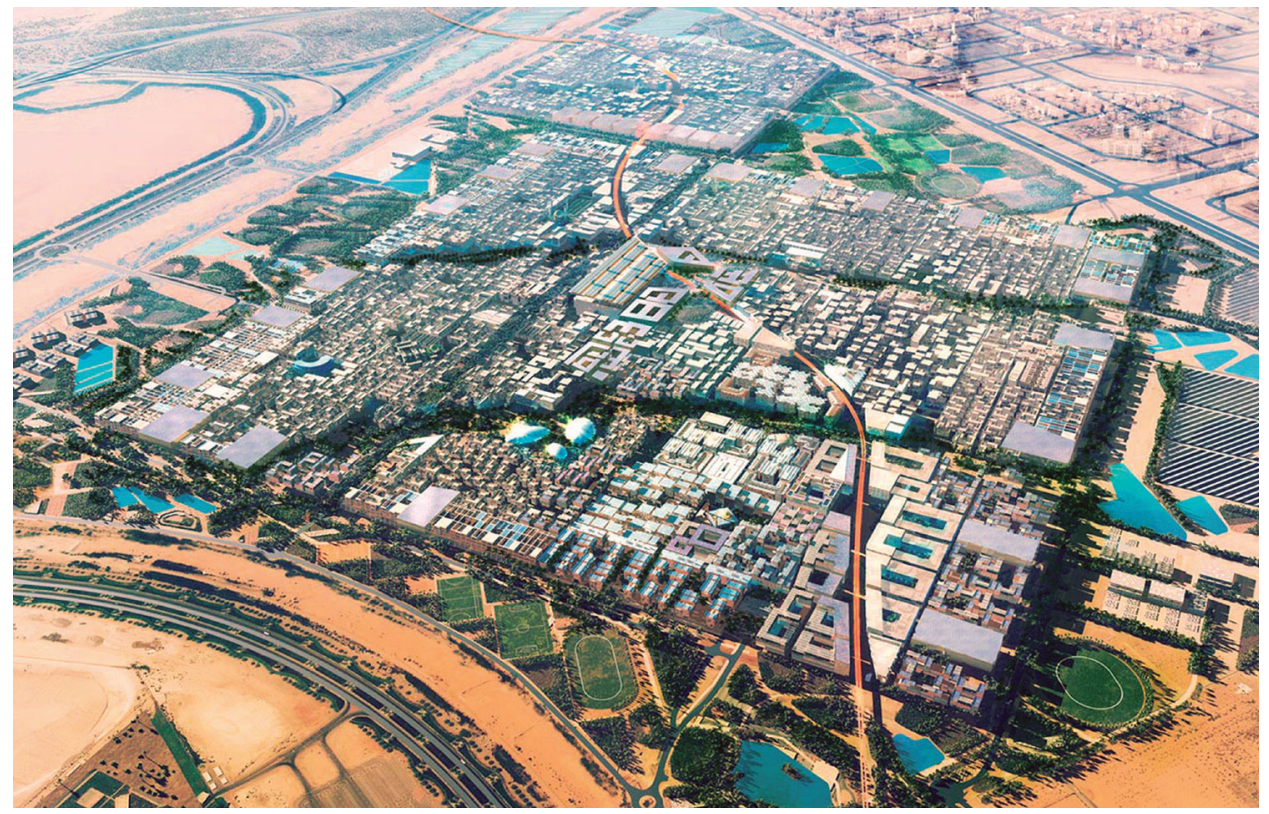

Figura 1. Master Plan Masdar (Foster \& Partners, 2008). 


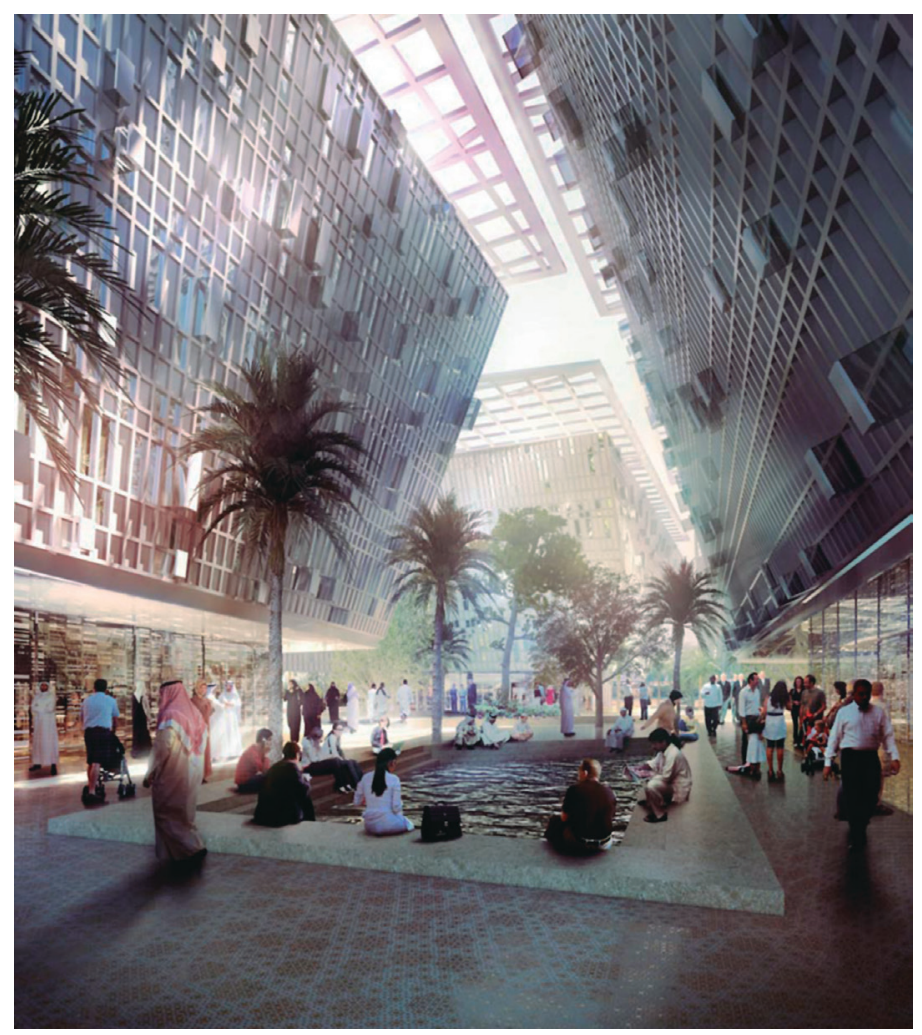

Figura 2. Calle interior (lb.).

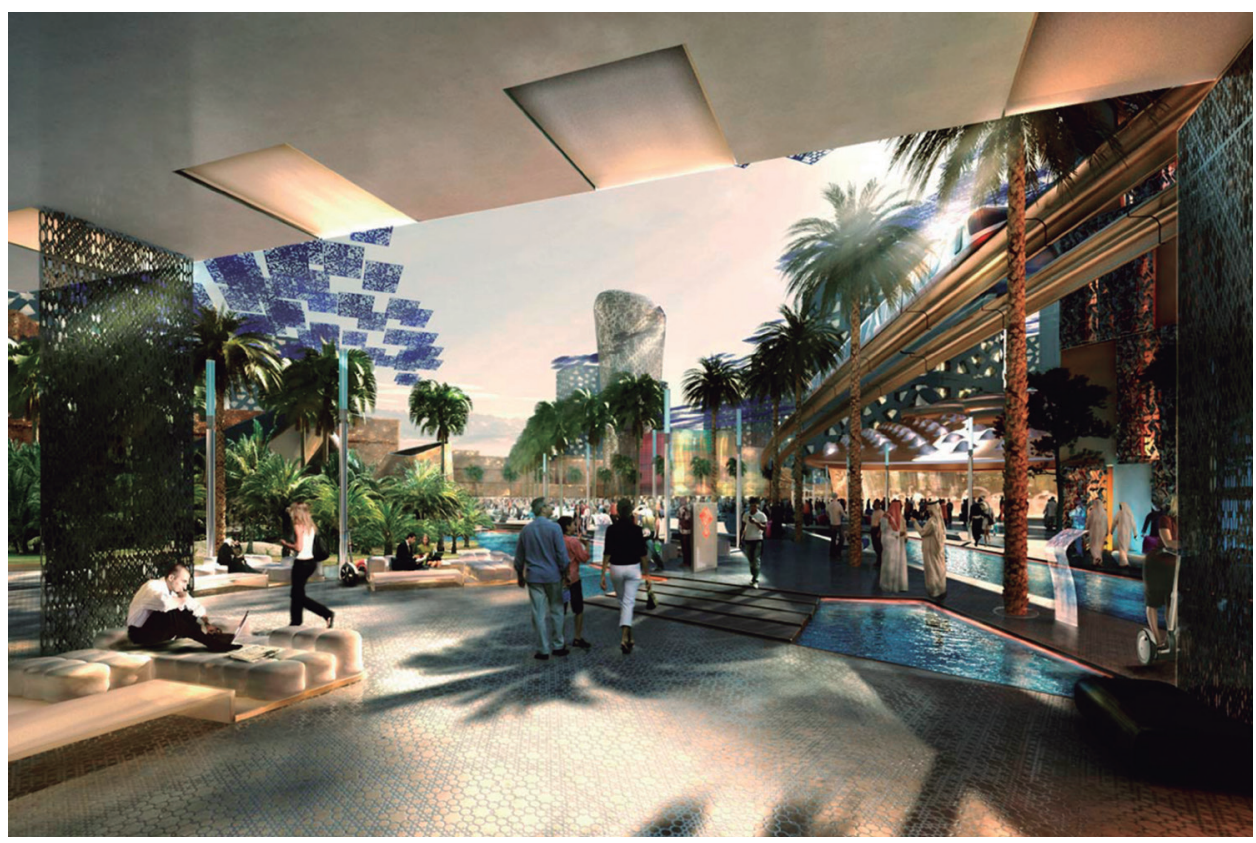

Figura 3. Espacio público semicubierto (Ib.). 
Tal como describe Galindo en su artículo sobre Masdar, con el propósito de fundar una ciudad eficiente, se torna fundamental adaptar el diseño al clima intenso de la región caracterizado por calores extremos y tormentas de arena. En este sentido, se unen al proyecto las costumbres de la arquitectura árabe tradicional y su evolución tras la aplicación de las últimas tecnologías vigentes. Con el objetivo de reducir veinte grados el clima medio, se emplean los siguientes recursos: un muro perimetral a la ciudad con el fin de servir de tamiz a las polvaredas, continuo de un anillo de vegetación. Para beneficiarse de las corrientes nocturnas y reducir así el impacto de la radiación solar; los pasajes son semicubiertos, angostos y oblicuos a la traza urbana (véase Figuras 1 y 2) a los que se suman la vegetación, los techos verdes y el equipamiento con agua para el descenso pasivo de la temperatura. En las construcciones privadas y en los espacios públicos son diseñados conductos árabes clásicos para retirar el aire caliente del día y ganar las brisas frescas de la noche. Además, las cubiertas, dispuestas en avenidas y zonas públicas son generadoras de energías limpias (véase Figura 3) (Ib., 2015).

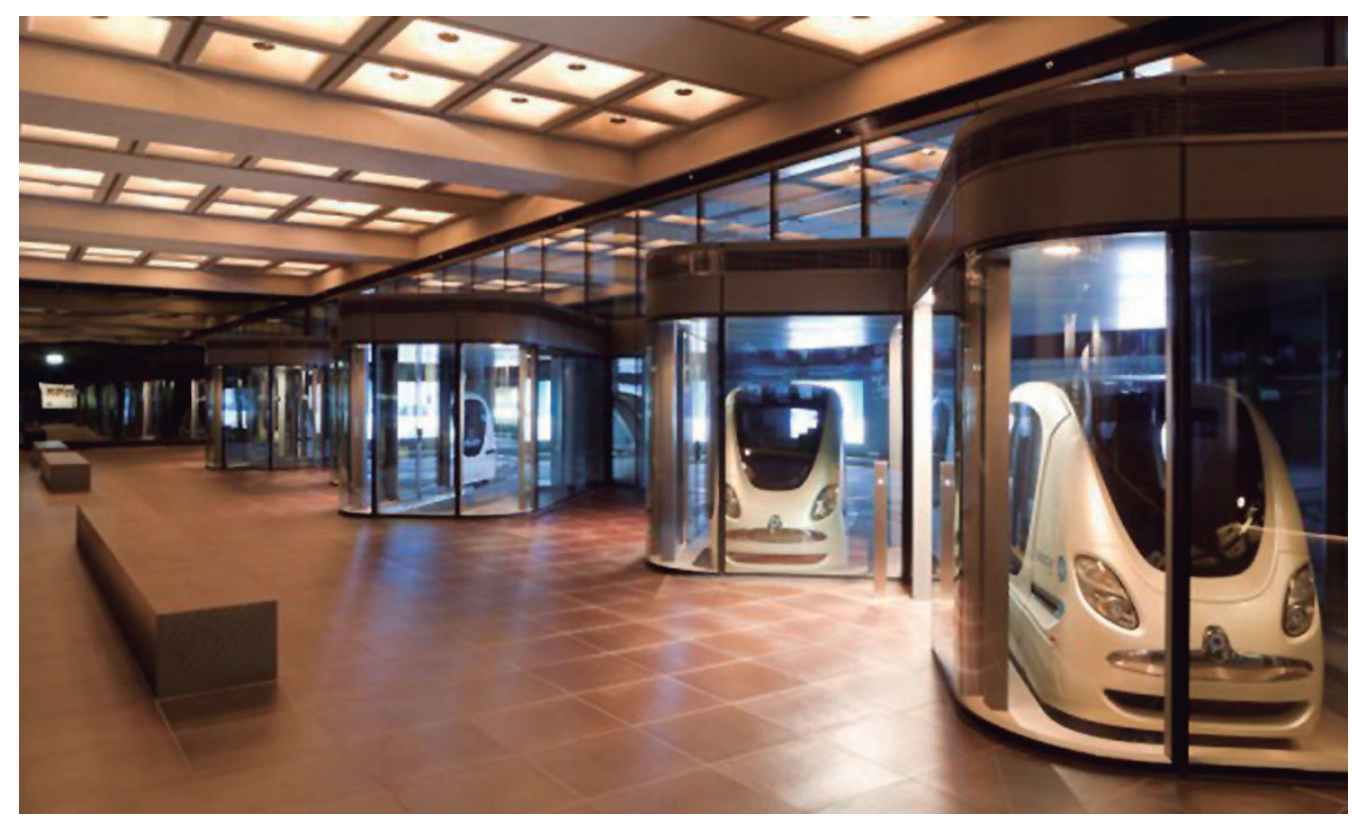

Figura 4. Servicio de taxis subterráneo (Masdar, a Mubadala Company, s.f).

"Masdar promete fijar los nuevos patrones para la ciudad del futuro", comenta Lacellotti y añade, que la nueva ciudad tiene como objetivo suprimir el uso del automóvil en su interior de forma concluyente con el propósito de eliminar las emisiones de carbono. Pretende cambiarlo por un transporte público que incluye tres sistemas. El primero consta de un servicio de taxis con prestación permanente, sin conductor y alimentados por células fotovoltaicas (véase Figura 4). El segundo constituye un sistema de raíl ligero que atraviesa toda la ciudad y conecta con el aeropuerto y la capital Abu Dhabi. Por último, un transporte de carga rápida para el traslado de alimentos y 
mercaderías, con el fin de aliviar las calles principales y ceder éstas para el uso peatonal únicamente, éste es accionado por medio de energía solar y contempla una flota de vehículos subterráneos sistematizados (Lancellotti, 2010).

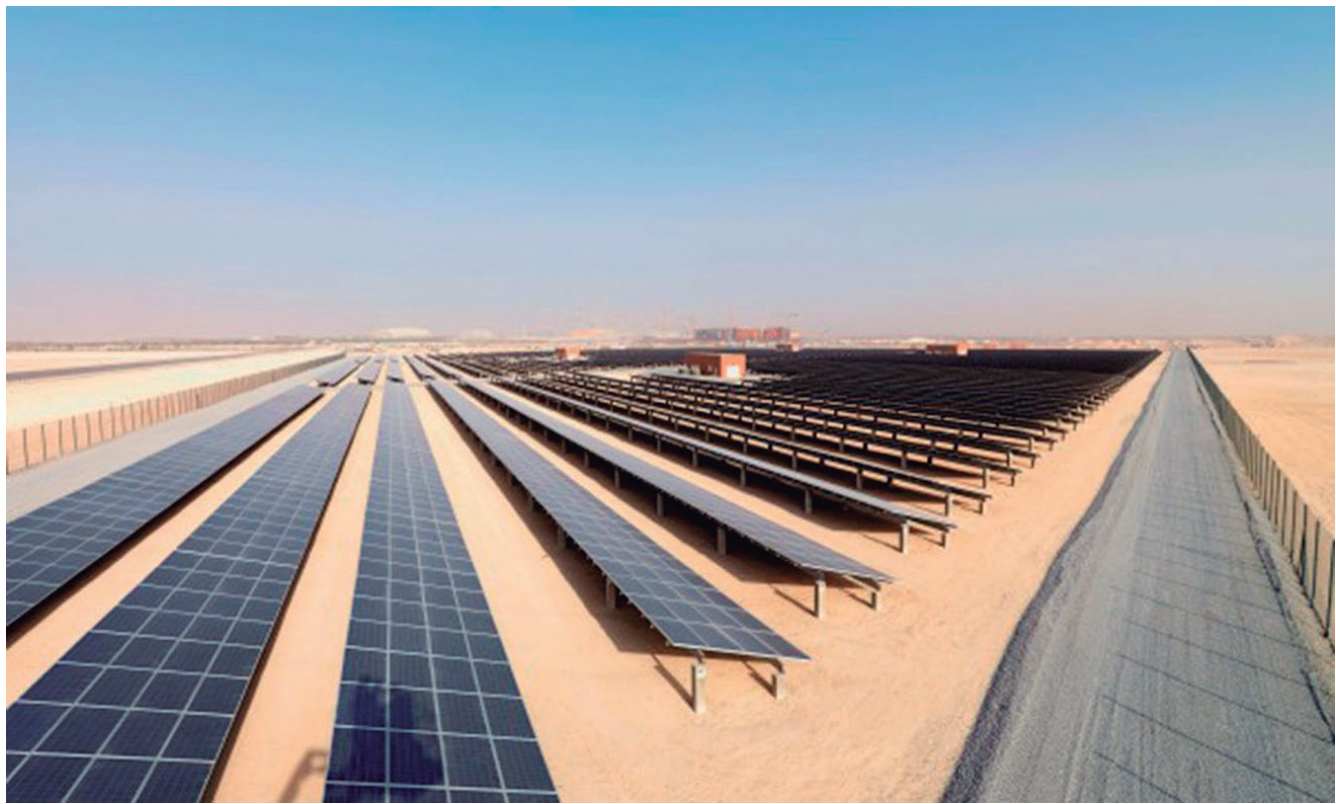

Figura 5. Planta de paneles solares (About Masdar clean energy, s.f).

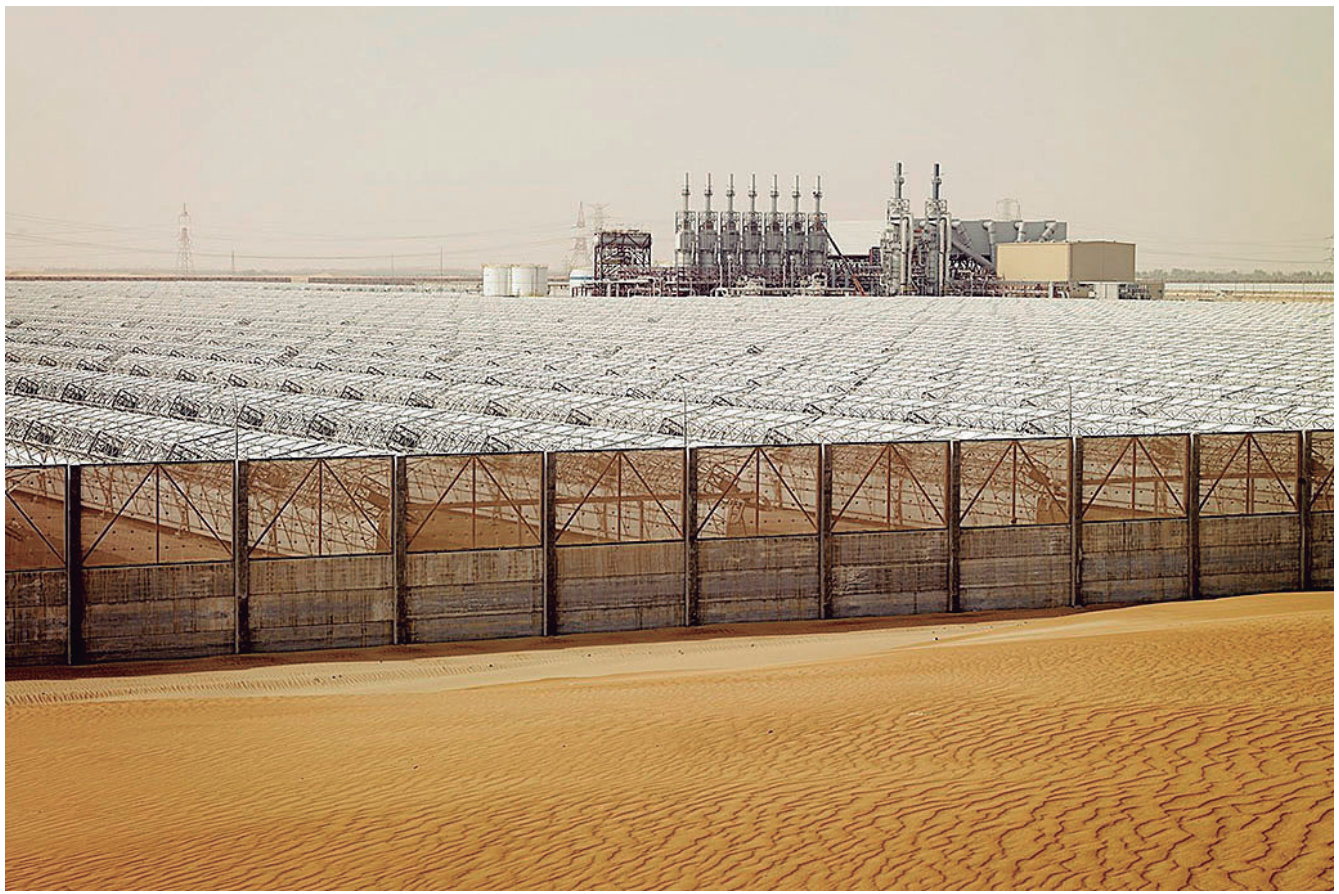

Figura 6. Shams 1. Planta de energía solar. (Antony, T., s.f). 


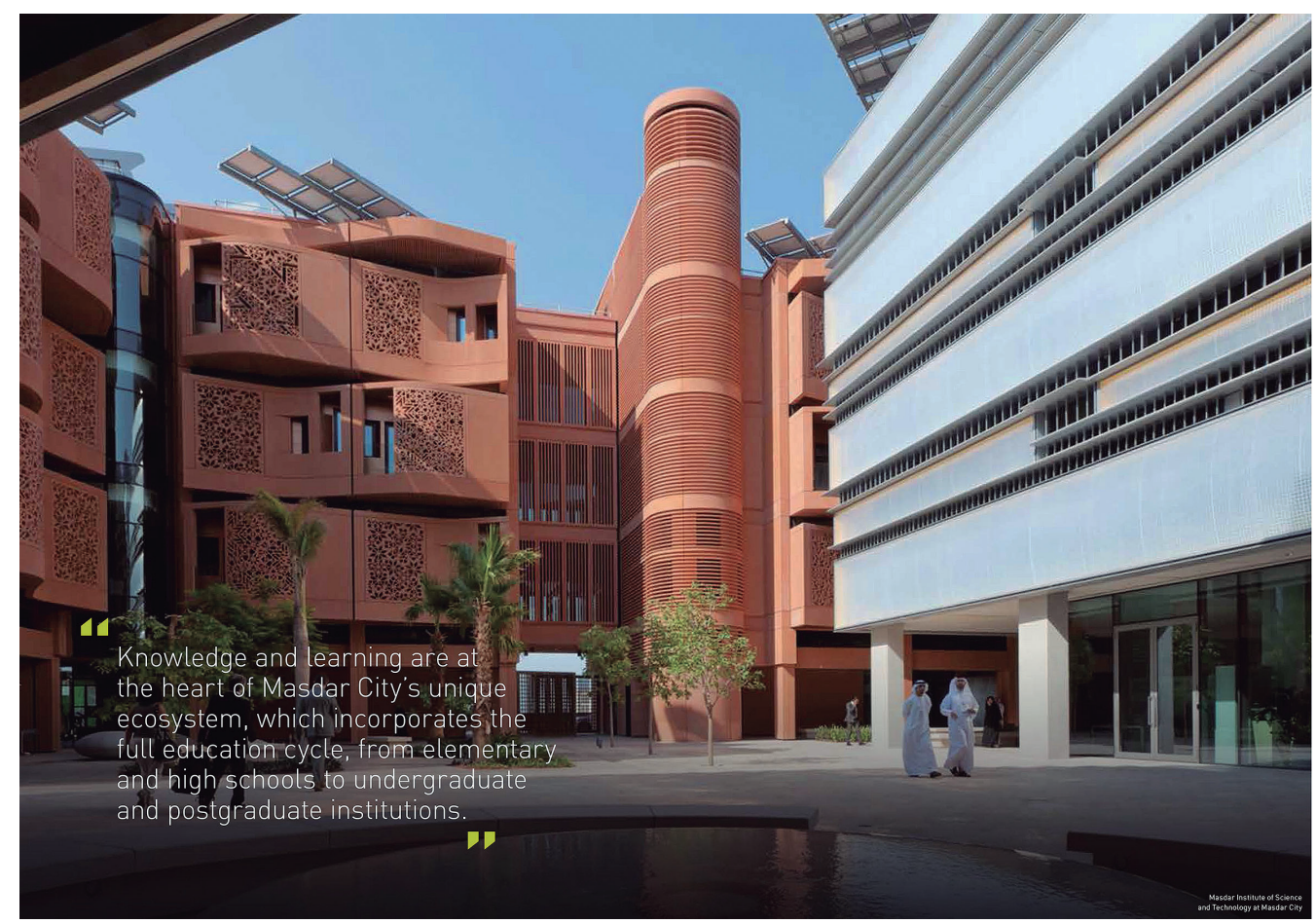

Figura 7. Centro de estudios académicos. (Masdar city, s.f).

La producción energética de Masdar se ha determinado en función de cálculos basados en la demanda racional de los recursos disponibles. La ciudad entera es alimentada por 87.777 paneles fotovoltaicos que se encuentran en un campo de 22 hectáreas de extensión (véase Figuras 5 y 6), a los que se les adicionan otros paneles solares que se encuentran en las terrazas de los edificios. El diseño de los muros de las edificaciones (amortiguados por cámaras de aire que limitan la radiación solar) ayuda a reducir la necesidad de acondicionamiento mecánico en un $55 \%$. No existen las llaves de luz ni los grifos, sólo sensores de movimiento; que según las autoridades de Masdar de este modo han recortado el consumo de electricidad en un 51\%, y el uso de agua en un 55\% (Kingsley, 2013). El proyecto ensaya también el tratamiento de aguas residuales y la recuperación de agua procedente de la evaporación, la cual pretende minimizar, a su vez, el empleo de la planta desalinizadora con que se ha dotado a la ciudad. La recuperación de residuos ha sido prevista para producir cero emisiones de $\mathrm{CO}_{2}$. Se calcula que el $50 \%$ de estos materiales podrán ser directamente reciclados y un $17 \%$ dedicado al compostaje. El resto, no reciclable, se utilizará como combustible en una planta incineradora subterránea. La cantidad estimada de residuos ronda las 350 toneladas diarias (Goitia, 2013).

La ciudad ha sido concebida para albergar 50 mil habitantes estables y 40 mil trabajadores y estudiantes externos. Uno de los proyectos emblemáticos dentro de 
Masdar es el Instituto de Ciencia y Tecnología (MIST), una colaboración sin ánimos de lucro para la investigación y el desarrollo entre el Instituto de Tecnología de Massachusetts (MIT) y Masdar (Jensen, 2015). Además de proponerse ser el centro académico por excelencia de las energías renovables y tecnologías limpias (véase Figuras 7 y 8 ), también busca ser el núcleo de absorción de startups y empresas mundialmente reconocidas en este mismo enfoque.

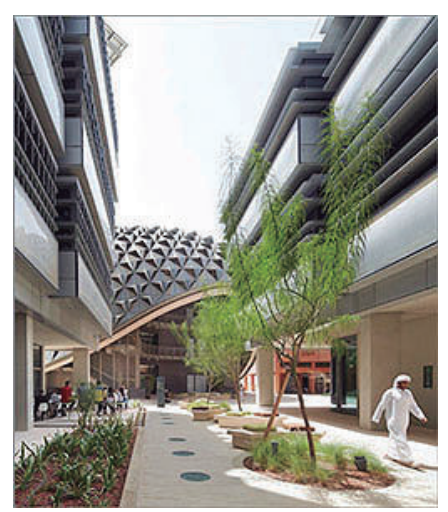

Figura 8. Laboratorios (Masdar, a Mubadala Company, s.f).

\section{Contexto de la ciudad ex-novo}

Se toma como referencia el artículo de la Dra. Graciela Silvestri 'Las múltiples disoluciones de la arquitectura' en el que desarrolla su mirada sobre la ciudad ex novo donde describe:

Masdar se encuentra en el emirato de Abu Dabi. Su capital, del mismo nombre, es la ciudad más rica del mundo: se encuentra literalmente sentada sobre las mayores reservas petroleras. En este territorio se hallan las famosas Saadiyat Islands, transformadas en un complejo de 30 billones de dólares, con 29 hoteles internacionales, tres marinas, dos canchas de golf, y habitación para 150000 personas. No se trata sólo de turismo, ya que en la capital se construyó la segunda mezquita más grande del mundo, y el palacio del Sheik ${ }^{3}$ parece emerger de Las mil y una noches. En el distrito cultural, se convocaron los nombres de los arquitectos más prestigiosos (Zaha Hadid, Tadao Ando, Jean Nouvel, Frank Gehry, Norman Foster), y los principales museos del mundo han cedido temporalmente parte de su patrimonio para ser exhibido. Tendremos, pues, otro Louvre, otro Guggenheim, otro British Museum. Para que esto se construya, no 
sólo deben importarse trabajadores -la mayoría de los habitantes proviene de Bangla Desh, India, Pakistán, Filipinas- sino, sobre todo, burocracias completas (2012, p. 196).

El proyecto de Masdar City no es una intervención solitaria, se trata del contexto tangible como parte de un plan para convertir la capital más rica del Golfo Pérsico en la eminencia a nivel global en exploración en sustentabilidad, incluyendo el estudio y perfeccionamiento de las energías renovables. Afirma Goitia sobre la ciudad:

será además la sede de la Agencia Internacional de Energías Renovables (IRENA). La compañía Masdar es una filial de Abu Dhabi Future Energy Company, dependiente a su vez de Mubdala Development Company, sociedad inversora del gobierno emiratí. Su máximo responsable, alteza Khalifa bin Zayed bin Sultan Al Nahayan, está impulsando importantes reformas de modernización desde que en noviembre de 2004 accedió al trono, tras la muerte de su padre y predecesor $(2013, p .87)$.

El presidente de $\mathrm{EAU}^{4}$ comprendió que la principal fuente de riqueza de Abu Dhabi (el petróleo), eventualmente llegará a su fin; por lo que pidió a sus asesores imprimir un plan a largo plazo que permita al país diversificar su economía lejos de los hidrocarburos. La respuesta fue: energía renovable (Kingsley, 2013). Fruto de tales intenciones surgió, en 2006 la iniciativa de Masdar City bajo el eslogan "algún día todas las ciudades serán como esta" (Expoterra, 2012).

\section{De la eco-ciudad a la ciudad futurista}

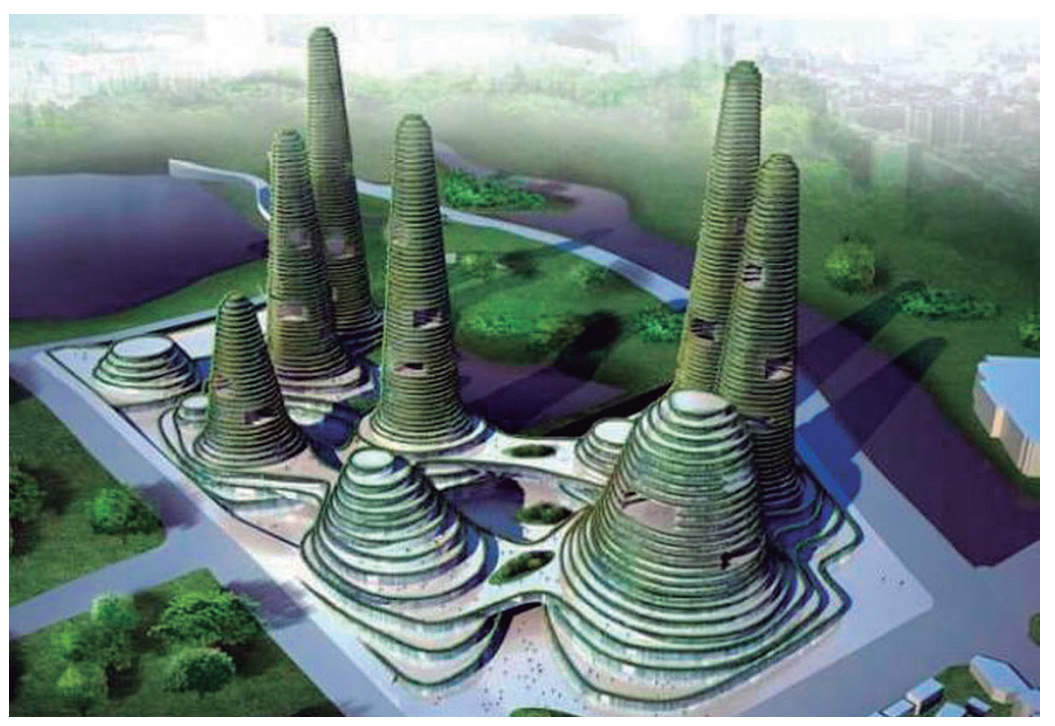

Figura 9.

Gwanggyo Power Centre

(Tuexperto, 2009). 


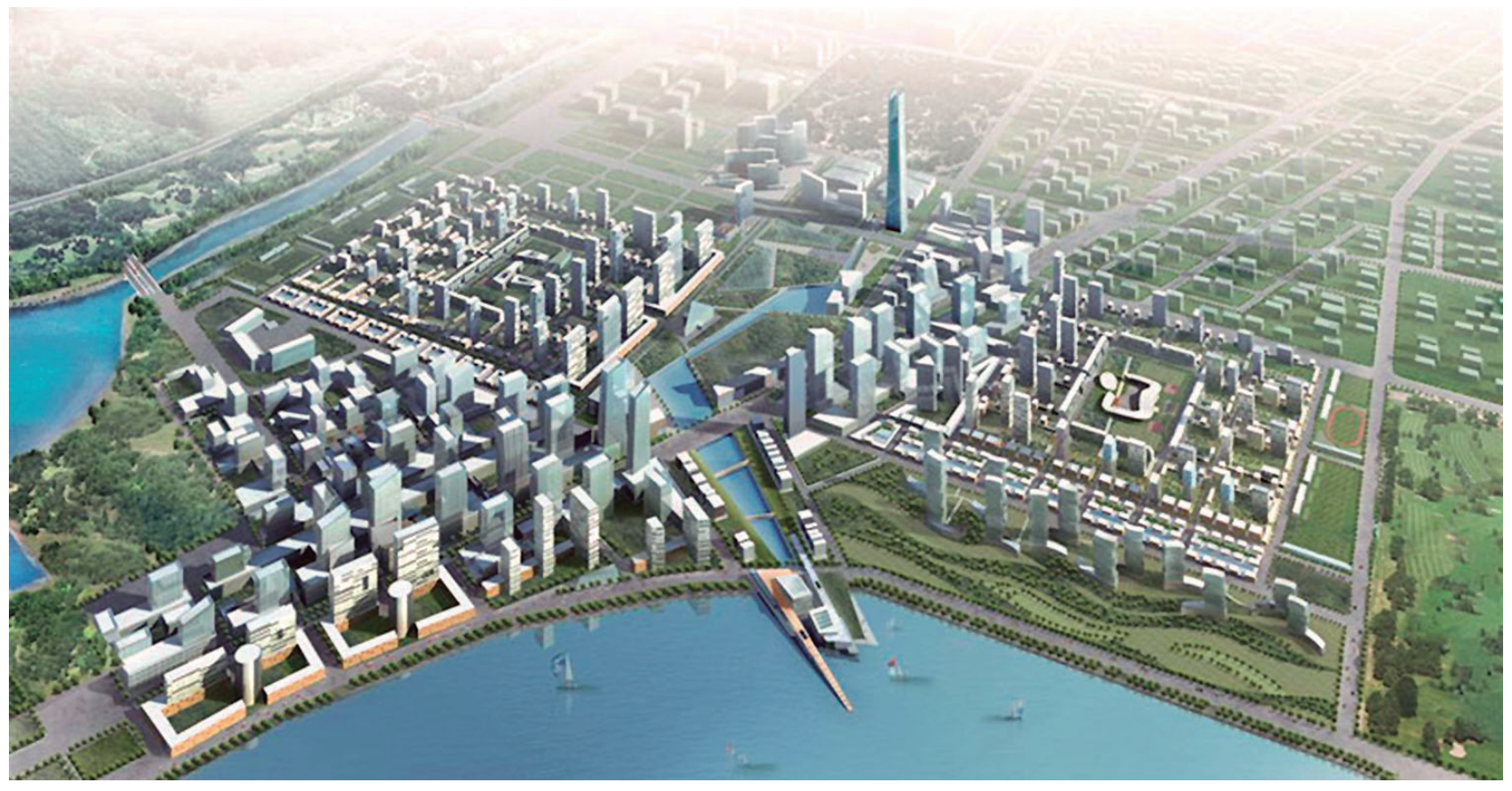

Figura 10. New Songdo City (Datuopinion, s.f).

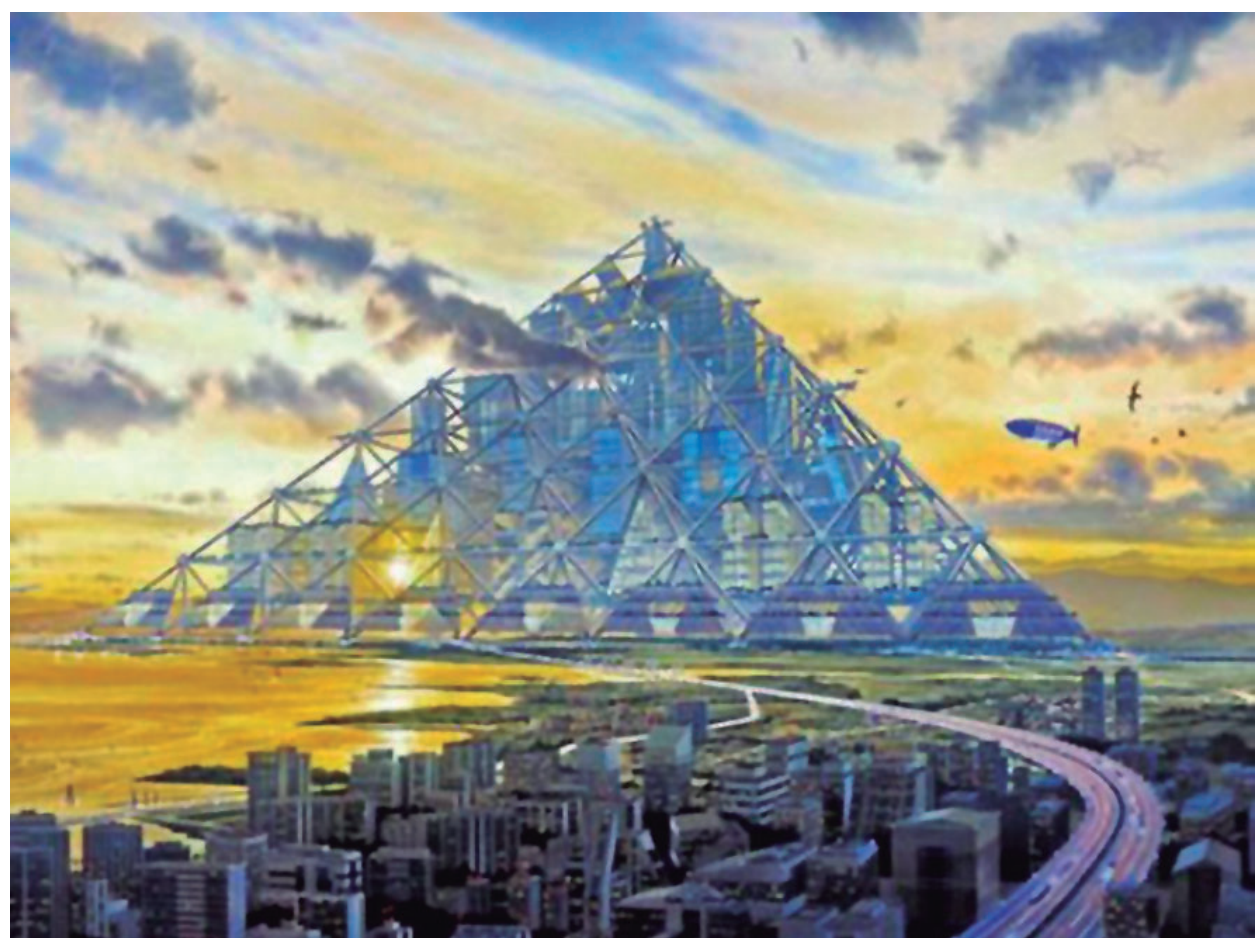

Figura 11. Shimizu Try 2004 (Ecodiario, 2011). 


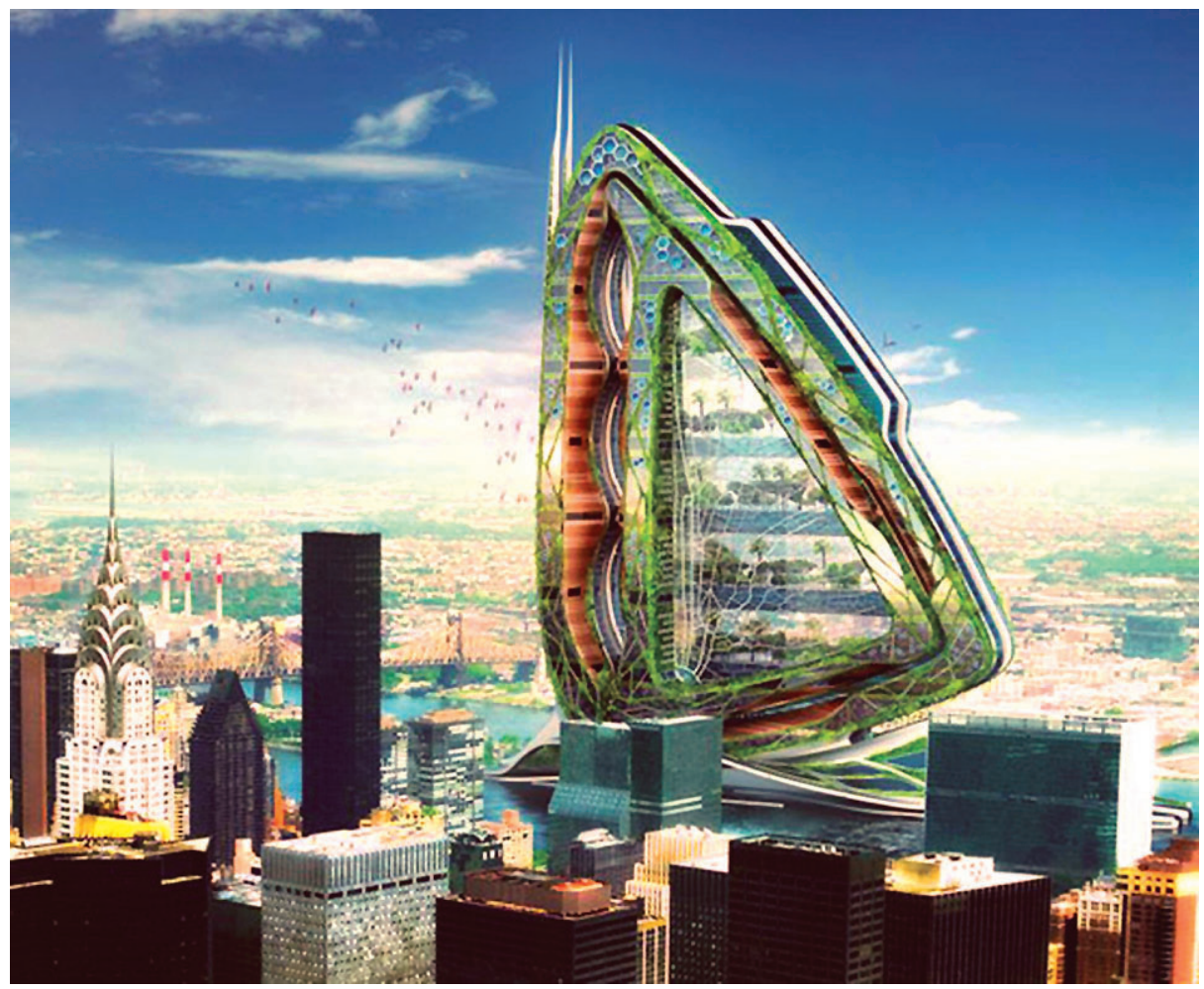

Figura 12. Dragonfly (Vincet Callebaut Architectures, s.f).

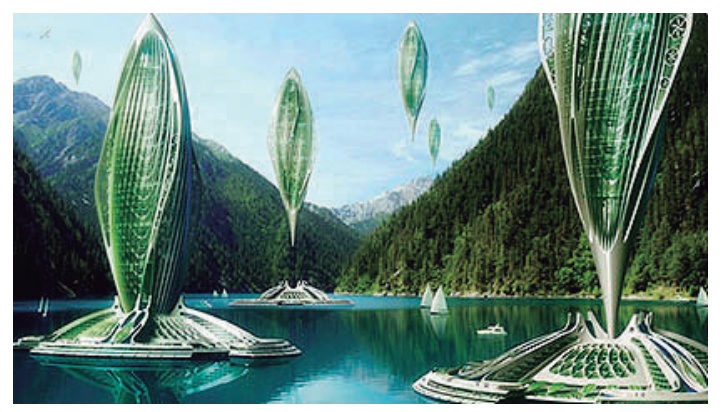

Figura 13. Hydrogenase (Callebaut, 2015).

En 2009 dos académicos de la Universidad de Westminster, Simon Joss junto a Daniel Tomozeiu, publicaron el primer informe de su investigación sobre eco-ciudades, que realizaron con el objetivo de clasificar sistemáticamente, analizar y comparar estas iniciativas (Hurtado, 2013). El principal enfoque ha sido intentar obtener un mejor entendimiento sobre la innovación y los procesos de gobernación que están conduciendo y formando desarrollos de eco-ciudades, buscando dar respuesta a las siguientes preguntas: ¿qué distingue a una eco-ciudad de una ciudad convencional?; ¿por qué las eco-ciudades parecen haberse convertido en la principal corriente en tan 
corto periodo de tiempo?; ¿y acaso pueden las eco-ciudades ser social y democráticamente sustentables? En su reporte los investigadores listan al menos 79 perfiles de eco-ciudades, pertenecientes a los cinco continentes. Lidera el continente europeo con al menos 30 ciudades analizadas, y seguido por Asia al cual le atribuyen al menos 25 eco-ciudades (Joss, 2010). El modelo eco-ciudad es ampliamente versátil. Propone desde variados puntos de vista y diversas iniciativas 0 acciones, modos de generar patrones de mayor sustentabilidad en las ciudades existentes, aunque también sugiere distintos modos y numerosas iniciativas para el desarrollo de nuevas expansiones e incluso nuevas urbanizaciones. Vale tener en cuenta que Masdar se encuentra catalogada dentro de esta clasificación. Dentro del término eco-ciudad en realidad lo que encontramos es que todas las ciudades, los asentamientos, las formas de vida urbanas en general pueden adaptarse a patrones de vida sustentables desde perspectivas muy diversas (Zamler, 2013). Existen tres modelos de eco-ciudad como una primera clasificación general: nuevo desarrollo, expansión de área urbana y readaptación del desarrollo. Las eco-ciudades tipo «nuevo desarrollo» (como Masdar City), son construidas desde cero completamente como nuevas ciudades, son bastante menos comunes que aquellas que se constituyen, ya sea como una expansión urbana o las de tipo readaptación (Joss, 2010).

La búsqueda de un modelo de ciudad nueva y futurista, utópica en algunos casos o más bien objetual, es un tema de actualidad. Existen diversos proyectos a nivel mundial que parecen una ciudad-objeto o ciudad-máquina. Estos tienen fuertemente en cuenta las tecnologías a utilizar, el empleo y desarrollo de energías renovables, autoabastecimiento energético y reducción de emisiones de carbono entre otras acciones. Visto que el urbanismo moderno aspiraba a alcanzar una estructura urbana coherente cuyo funcionamiento fuera similar al de una máquina y, al mismo tiempo, contuviera los atributos del organismo biológico, se podría trazar un paralelismo entre la ciudad-máquina del movimiento moderno y los ejemplos tanto de Masdar como urbe futurista, así como con otras iniciativas halladas en diferentes países que buscan proyectar la ciudad del futuro. Entre algunas de ellas se encuentran: Gwanggyo Power Centre $^{5}$, una metrópoli autosuficiente, compleja, dinámica, con capacidad para más de 77.000 habitantes (véase Figura 9) y New Songdo City ${ }^{6}$, un centro de negocios y de libre intercambio económico (véase Figura 10), ambas en Corea del Sur; Ciudad Shimizu Try 20047, una ciudad constituida por 55 pirámides cuya estructura tendrá al menos 2.004 metros de altura, podría alojar 750.000 personas, una respuesta para la creciente carencia de espacio en Tokio (véase Figura 11); Dragonfly ${ }^{8}$ una estructura bioclimática basada en la energía proveniente del sol y el viento con un diseño de granja vertical donde se cultivaría comida, además de servir como granja y fuente de energía renovable dentro de un emplazamiento urbano en la Isla de Roosevelt en Nueva York (véase Figura 12); e Hydrogenase", caracterizada por la capacidad de "elevarse hasta los 2.000 metros a $175 \mathrm{~km} / \mathrm{h}$ en caso de desastre natural, tan solo propulsada por su propio biohidrógeno" (El Economista, 2011), en Shangai, China (véase Figura 13). Este 
último parece ser el proyecto más ferviente de los vistos hasta ahora como ejemplo literal de una máquina futurista. Dentro de este contexto, para la reflexión acerca de este tipo de proyectos, cabe recordar algunas palabras de Le Corbusier (1924):

Habiendo el siglo de la máquina desencadenado sus consecuencias, el movimiento se ha apoderado de un instrumental nuevo para intensificar su ritmo; lo ha intensificado con tal aumento de velocidad que los acontecimientos han superado nuestra capacidad receptiva y el espíritu, generalmente más pronto que la realidad, ha sido esta vez, en cambio, superado por ella con su aceleración siempre en aumento (...). El ritmo se ha acelerado al punto de poner a los hombres (...) en un estado de inestabilidad, de inseguridad, de fatiga, de alucinación creciente (p. 54).

\section{Miradas sobre Masdar}

Abundan las opiniones que desaprueban el megaproyecto por las paradojas que presenta. Por un lado, fundar una ciudad nueva, limpia de emisiones de hidrocarburos en la misma región que es productora del petróleo y causante del empeoramiento ambiental a nivel mundial y del otro por el prominente costo económico del diseño. Si bien desde otra mirada pareciera prudente o lógico que quien ha desarrollado la primordial provisión de energía convencional al mundo, sea hoy día quien busque desarrollar nuevos modos de energías limpias y alternativas con el objetivo de continuar liderando este sector del mercado (Goitia, 2013). Según las palabras de Silvestri (2012):

Masdar es la perla verde de las intervenciones en Oriente Medio, cuya expansión económica deriva de la oportuna articulación de la crisis global de Estados Unidos y Europa occidental, con la liquidez financiera de los países exportadores de petróleo del Gulf Cooperation Councill1. Pero hoy los países del Golfo son más estratégicos en sus apuestas: la provisión de infraestructura y desarrollo inmobiliario en la propia tierra adquirieron un lugar relevante, con el objetivo de colocar estas naciones en el orden mundial, especialmente en lo que atañe a la creación de atractivos turísticos para sectores exclusivos (p. 196). 


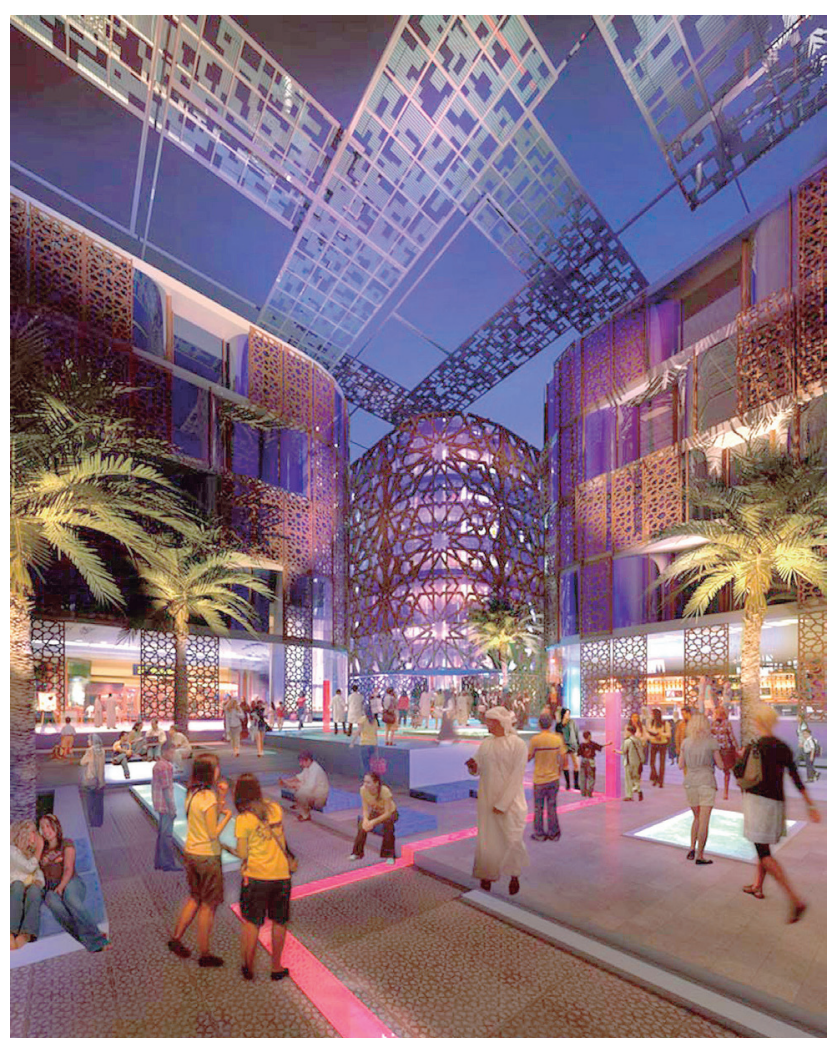

Figura 14. Calle interna (Foster \&Partners, 2008).

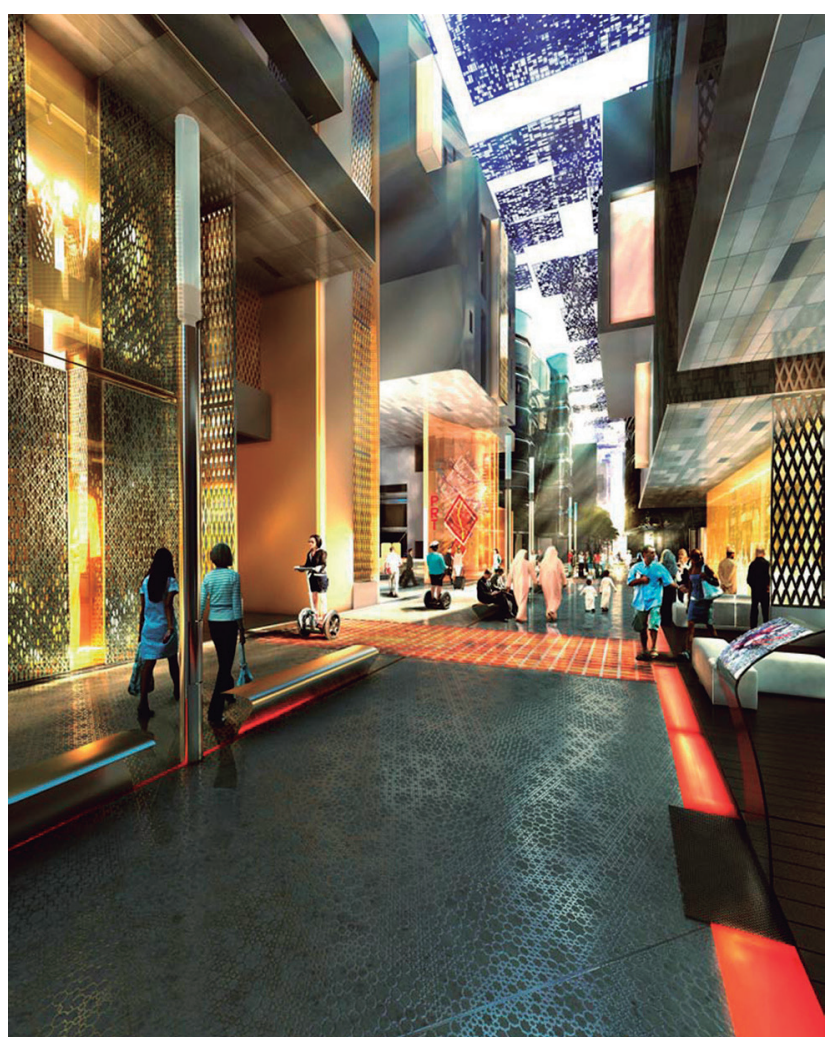

Figura 15. Calle interna (Ib.).

La ambición del proyecto resulta realmente loable, aunque se debe destacar que las ilustraciones que se presentan parecieran muy similares a las de un shopping de diseño árabe tradicional (véase Figuras 14 y 15). Por ello cabe preguntarse si la nueva urbanización parece un centro comercial, acaso podría tratarse de un bien particular que se beneficia del concepto sustentabilidad como una captación adicional del cliente o futuro residente urbano, alejándose éste del entendimiento más amplio del concepto ciudad (Ib., 2012).

Resulta asombroso que un país acaudalado por los hidrocarburos, que se conoce en el mundo como uno de los mayores responsables de los impactos ambientales, emprenda una urbanización como Masdar. Siendo ésta para tan sólo 50 mil nuevos residentes, mientras que actualmente en los EAU viven cinco millones de habitantes. Pareciera entonces que erigir la nueva ciudad en tal escala y que produzca cero residuos y emisiones de dióxido de carbono "solo producirá un efecto marginal en la reducción de emisiones a la atmósfera tomando en cuenta todo el país", opina Oikonomidou (2012). Al reflexionar en la cercanía de algunas de las novedosas iniciativas Ilevadas a cabo en Dubai, como un complejo de islas artificiales o las pistas de sky, a la novedosa urbe ecológica Masdar, el concepto sustentable parece perder autenticidad 
y responsabilidad frente al mundo. Agrega la autora "tomando en cuenta el origen del financiamiento de la ciudad los escépticos dicen que es solo una forma inteligente para hacer quedar bien a Abu Dhabi mientras continúa haciendo lo que sabe hacer mejor, bombear petróleo" (Ib.).

\section{Situación actual de la ciudad del futuro}

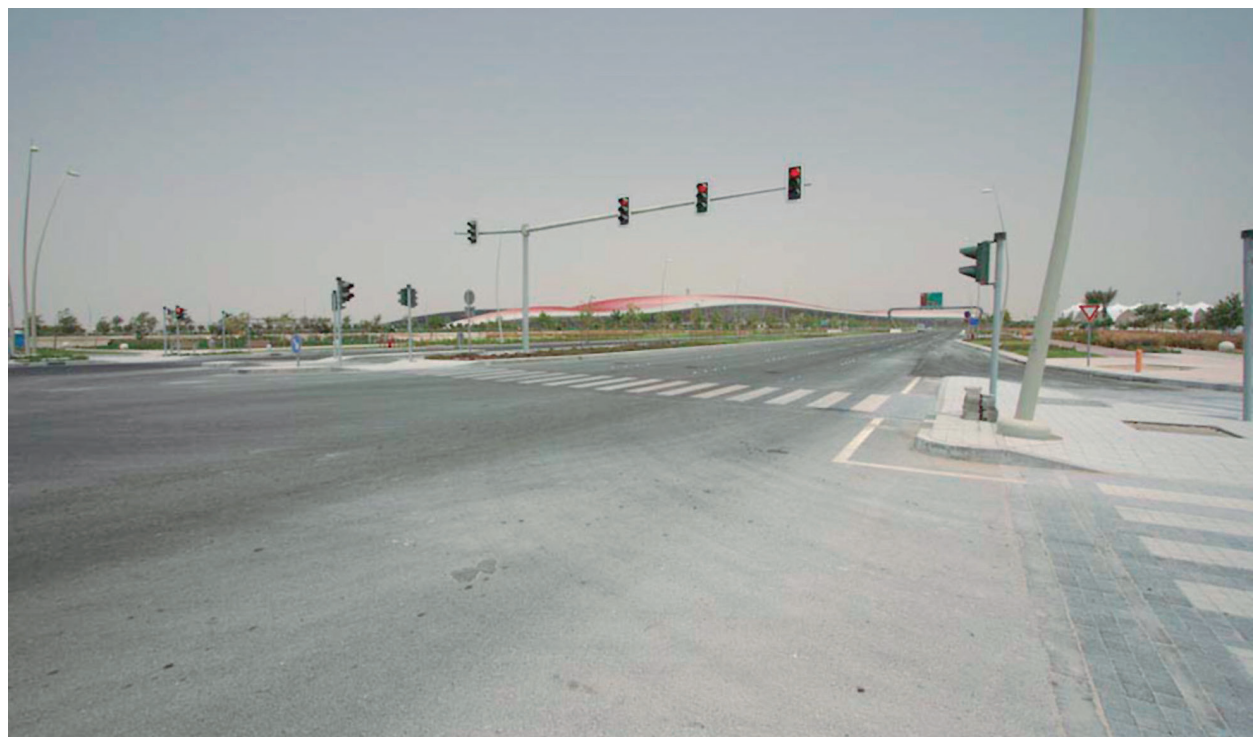

Figura 16. Ingreso a Masdar (Masdar City: A Critical Retrospection, s.f).

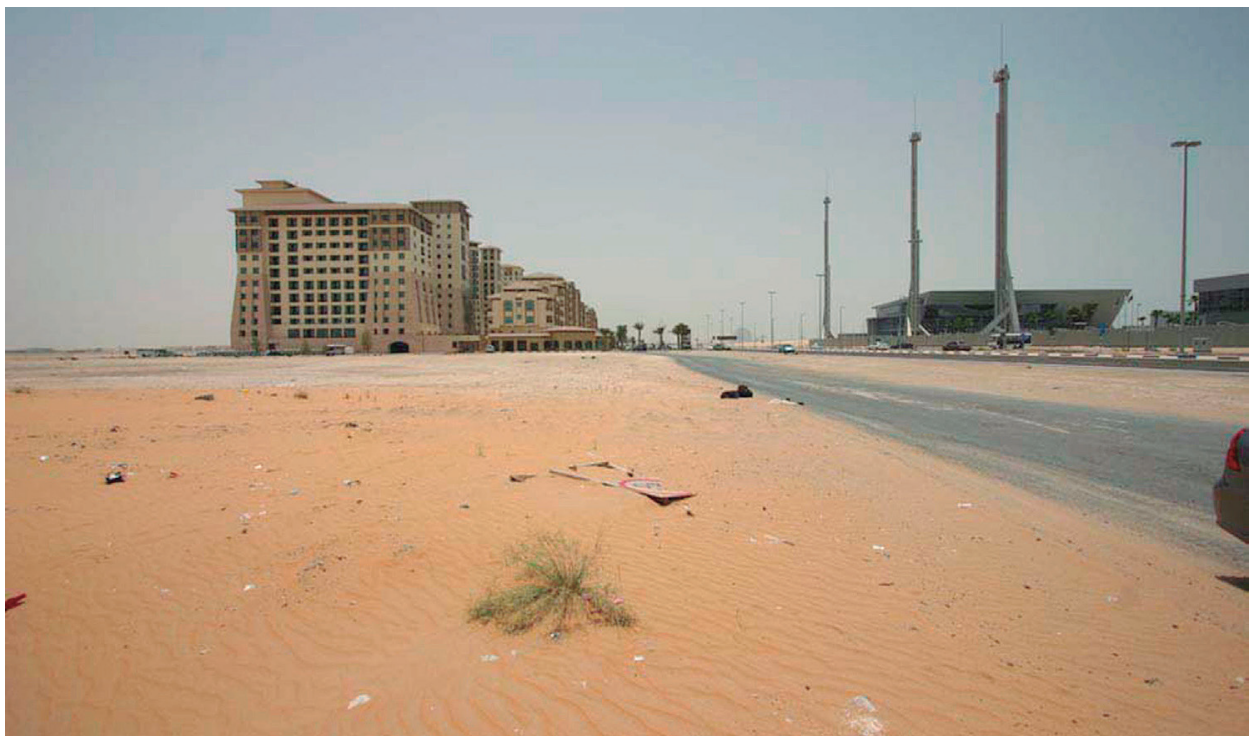

Figura 17. Estado actual Masdar (lb.). 
El colapso del mercado financiero en 2008 comenzó a causar turbulencia para el proyecto de Masdar City. Numerosos reportes sobre esperados retrasos en las próximas etapas, reajustes financieros al presupuesto inicial de 22 billones de dólares y modificaciones en el esquema original empezaron a aparecer en los diarios del mundo. En octubre de 2010 el nuevo (ahora también anterior) director de Masdar, Alan Frost, comentó a periódicos locales que el plan de producir toda la energía que alimente a Masdar de forma local, estaba siendo reconsiderado (Jensen, 2015). La última fecha establecida para dar fin al proyecto, prevista para el 2016, ha sido pospuesta hasta una incierta fecha futura en orden de crecer 'orgánicamente' con las fuerzas del mercado (Mandel, 2010). La única predicción definida acerca de Masdar es que nunca será construida acorde al Master Plan ${ }^{11}$ original (véase Figuras 16 a 19).

El investigador Boris Borman Jensen ${ }^{12}$ relata:

Fui a Masdar City en 2010 con altas expectativas, pero no me fue permitido tomar ninguna fotografía in situ. La pregunta es: ¿por qué este espectacular conglomerado de representantes del Estado, arquitectos mundialmente destacados, ingenieros especializados, ambientalistas de pensamiento empresarial y constructores corporativos de ciudades insisten en semejante control sobre información esencial? Entre otros motivos, los funcionarios oficiales del gobierno que trabajan para la compañía responsable del proyecto de Masdar City o cualquier empleado en el lugar puede ser acusado de perjudicar la economía nacional si participan de un debate público acerca del proyecto o cuestionan sus condiciones generales (2015).

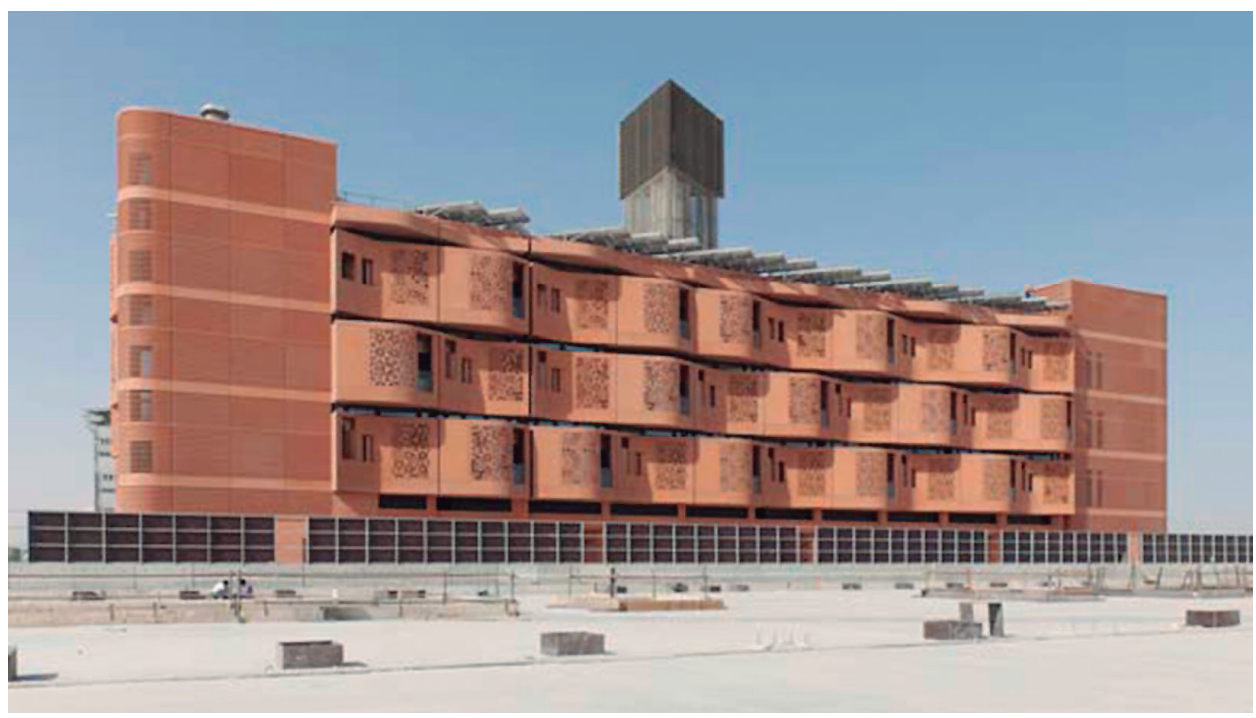

Figura 18. Masdar bajo construcción (Foster \& Partners, 2008). 


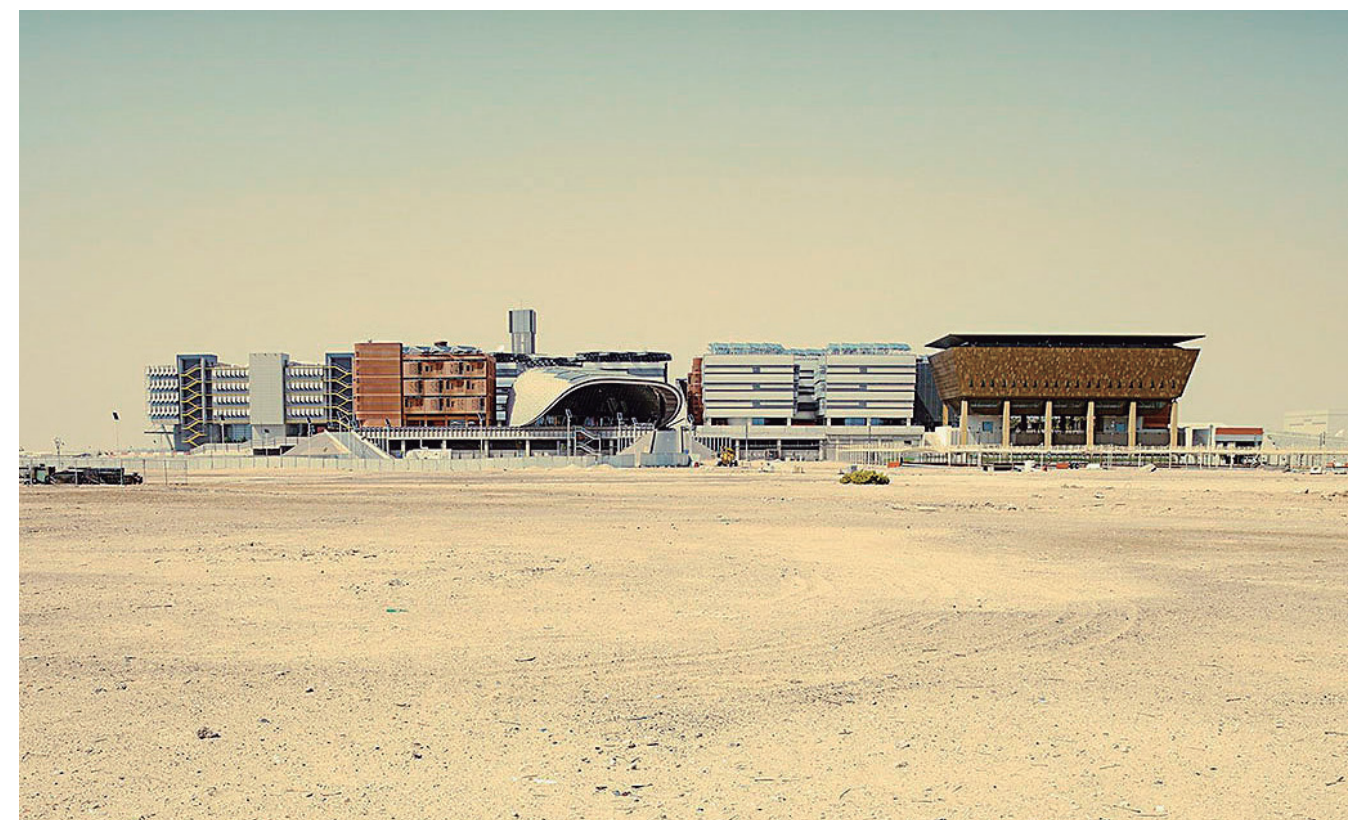

Figura 19. Masdar actualmente (Antony, T., s.f).

Una búsqueda rápida en Google con el título 'Masdar City', en 2010 dio lugar a más de cinco millones de resultados, lo que de alguna manera confirmaba la prominencia del proyecto. Hoy el número ha bajado a cerca de medio millón de resultados (Ib.). El análisis de esta información en su conjunto da cuenta de la falta de información actualizada sobre la situación actual del proyecto, la caída de interés general acerca del mismo y la cantidad de interrogantes que se abren acerca de la primera ciudad $100 \%$ sustentable del mundo.

\section{Preguntas y reflexiones acerca de Masdar City}

¿Cuál es la fuente de inspiración estratégica de Masdar para su emplazamiento? ¿Será acaso el predominio del sol en ese lugar, sobre el que se afirman las energías renovables? ¿Será ése el eje fundacional y el rol de la nueva ciudad? Pareciera difícil encontrar otra riqueza natural, histórica o cultural que hagan de este lugar específico un atractivo a nivel mundial, más allá de lo propuesto por el Master Plan. Parece, entonces, que se estuviera fabricando un paisaje, un atractivo, un motivo para llevar adelante este nuevo megaproyecto.

Dentro del concepto de ciudad como un sistema interrelacionado de actividades, donde juegan variables de orden político, económico, social, cultural y físico, subsistema a su vez de esquemas más amplios, sujetos al cambio del tiempo.

Dentro del concepto de ciudad en sí, se interrelacionan diversas disciplinas como la política, la economía, la sociología, el urbanismo, la arquitectura, la antropolo- 
gía, entre otras dentro de las cuales intervienen otros subsistemas y dimensiones como la cultural, la física, la ambiental, etc., (Yujnovsky, 1971). Entre otros el reconocido arquitecto Richard Rogers ${ }^{13}$ (2003) argumenta que las ciudades funcionan de atractivos demográficos porque facilitan trabajo y son la base del desarrollo cultural. Afirma:

Son centros de comunicación y aprendizaje y de complejas estructuras comerciales, albergan densas concentraciones humanas y focalizan la energía física, creativa e intelectual. Son emplazamiento de actividades y funciones altamente diversificadas: exposiciones y manifestaciones, bares y catedrales, tiendas y auditorios. (...) combinación de edades, razas, culturas y actividades, la mezcla de comunidad y anonimato, familiaridad y sorpresa, e incluso el sentido de peligrosa excitación que suscitan (p. 15).

Se sugiere preguntar entonces ¿cuál es el rol de Masdar? Hemos visto que uno de sus fundamentos es el objetivo de convertirse en el centro mundial por excelencia para la investigación en energías renovables, el desarrollo y la innovación. Entonces, ¿qué va a pasar con Masdar una vez que, como el petróleo, pase la era del desarrollo e investigaciones para las energías renovables? ¿Tendrá entonces un nuevo rol? ¿Podrá con los años y el transcurso de la historia encontrar nuevos roles y diversificarse? ¿0 acaso pasará a convertirse, como Detroit ${ }^{14}$ en una ciudad fantasma? Una vez que los nuevos habitantes se asienten en Masdar, se hayan trasladado estos por estudio o trabajo y cumplan con su objetivo, ¿elegirán quedarse allí? ¿Cuál será el sentido de pertenencia de los habitantes de Masdar para con la ciudad?

Cuando surge entonces la pregunta ¿por qué existen las ciudades?, se adoptan los conceptos de Ascher (2012):

más allá de las épocas, los modos de producción, las culturas y los contextos, lo que tienen en común las ciudades es que ofrecen más posibilidades que las demás formas de asentamiento humano (...). Lo que singulariza a las ciudades proviene, en primer lugar, de la numerosidad. Aunque no constituye en sí misma una garantía, la numerosidad ofrece más posibilidades que los pequeños grupos (...). La ciudad atrae a los que esperan algo de la numerosidad, por la fuerza que engendra o por las alternativas que propone, por la posibilidad de reunirse con «semejantes» o juntarse con otros, por las mayorías que constituye o por las minorías cuya existencia permite. No obstante, para que el potencial que produce el agrupamiento de personas y de riquezas que van con ellas se haga efectivo, se requiere de un poder capaz de organizar la ciudad con este propósito (p.163). 
De acuerdo a la exposición de Rondon (2009) cuando hablamos de sustentabilidad, se pretende la asimilación de una forma de vida y de tratamiento responsables con el ambiente y la sociedad, conforme con las nociones de sustentabilidad ecológica, equidad social, ética y responsabilidad transgeneracional, las cuales provienen del concepto original, el cual define sustentabilidad como el estilo de desarrollo -social, cultural, económico y ecológico- tal como manifiesta el autor citando el informe Brundtland 1987, "que permite satisfacer las necesidades del presente sin comprometer la capacidad de las futuras generaciones para satisfacer sus propias necesidades" (Brundtland, 1987; Kelly, 1998; citado por Rondón, 2009).

¿Diseñar una planta desalinizadora para abastecimiento de agua, no es acaso una acción similar a la que ha consumado Luis XIV que, para la construcción del lago, las fuentes y los servicios Reales en el Palacio de Versalles ${ }^{15}$, se debió conducir el agua por medio de acueductos, cuyo coste fue tan grande como el propio Palacio? Cierto es que hoy la desalinización del agua empieza a cobrar protagonismo en variados países de distintos continentes con escasez de agua dulce. Si bien el agua es el líquido más abundante en el mundo, una pequeña porción de esta es apta para el consumo del hombre; de un total del $100 \%$ del agua existente, un $97,5 \%$ es salada y sólo el 2,5\% es dulce, y sólo un $0,3 \%$ es la cantidad disponible para el consumo humano. Pero no se puede dejar de lado el costo que implica la inversión de la desalinización del agua; sumado al coste de energía, mantenimiento, y por supuesto el costo ambiental de dicha operación (Dévora-Isiordia, González-Enríquez, \& Ruiz-Cruz, 2013). Por tales motivos surge la pregunta, ¿es acaso Masdar la inversión sustentable que el mundo necesita, teniendo en cuenta la cantidad de carencias, necesidades de mejora y acciones que nos quedan por llevar a cabo en las ciudades existentes de todos los continentes? Este tipo de megaproyectos tienen como destinatarios a los ciudadanos de mayor poder adquisitivo, así como los barrios cerrados, mientras que los habitantes que carecen de vivienda y son marginados en las ciudades existentes, siguen careciendo de vivienda y siguen siendo marginados. Así es que la ciudad ex-novo Masdar, con una inversión multimillonaria por detrás, se convierte en un proyecto futurista en vistas de posicionar a los Emiratos Árabes un escalafón más alto dentro del mundo occidental, y sin embargo, es en los mismos países árabes donde cientos de miles de residentes carecen de vivienda, de infraestructuras y de seguridad social, donde la moneda más corriente es la falta de calidad de vida de los habitantes. Por ello particularmente se debe cuestionar la sustentabilidad del megaproyecto.

Se debe recordar que la palabra latina civitas designa una pluralidad de seres humanos unidos por lazos sociales y debe su nombre al de los ciudadanos (cives). Bajo este concepto no hay ciudad sin ciudadanos, y difícilmente habrá ciudadanos sin una historia, sin una cultura, o simplemente un motivo de arraigo en su ciudad. Pareciera entonces, que fabricar una ciudad futurista, es crear un objeto altamente eficiente en cuanto a su tecnología y consumo energético; pero al menos hasta ahora, no demuestra igual eficiencia en la consideración del rol del ciudadano, el cual inevitablemente 
le otorga el rol a la ciudad.

Masdar no es una ciudad en el entendimiento convencional del término. Es en cambio, un sofisticado proyecto de urbanización eco-tecnológico a gran escala, y el Master Plan es esencialmente un modelo de negocio ilustrado, construido por la Compañía de Energía Futura de Abu Dhabi, como una propiedad privada con un único dueño. Masdar City podrá posiblemente ser algún día al mismo tiempo animada y densa. El Master Plan tiene una clara aspiración por representar al gunas de las complejidades programáticas de una ciudad 'real'. Tendrá alojamiento para invitados, lujosos departamentos para CEO's, muchos comercios y oficinas, (tal vez) un sistema de transporte rápido y personal. Masdar será un refugio seguro y libre de contaminación, y un centro de trabajo y vivienda de primera categoría. Y tendrá casi todo lo que cualquier ciudad próspera tiene, incluyendo espacios verdes, diversión y espectaculares vistas. La nueva ciudad nunca tendrá que lidiar con industria pesada, plantas químicas, agricultura contaminante 0 incluso vivienda para obreros de la construcción del tercer mundo. Probablemente tendrá abundantes barrios ricos con muchos locatarios, una afluencia de expatriados y otros visitantes, pero no ciudadanos. Es posible que algún día tenga grandes calles e incluso grandes centros urbanos diseñados por jóvenes y hábiles arquitectos, pero nunca tendrá algún espacio público real (Jensen, 2015).

\section{Conclusiones}

Masdar viene a ser el ejemplo de ciudad futurista con patrones de sustentabilidad ecológica más destacado de la actualidad. Hoy, con el desarrollo de la tecnología, son muchas las medidas que se pueden implementar, en cualquier tipo de clima y geografía, e incluso en diversos contextos económicos, políticos y sociales, a fin de poner en práctica las conclusiones a las que hemos llegado tras dos siglos de despilfarro de recursos naturales limitados ${ }^{16}$.

Partimos de la existencia de un consenso básico entre los estudiosos sobre «la revolución urbana» que caracteriza el proceso de urbanización a partir del último cuarto de siglo XX. La urbanización no genera necesariamente ciudad. El viejo concepto de «área metropolitana» (...) ha sido desbordado por el desarrollo de una urbanización regional, multiescalar, en la que se encuentran núcleos urbanos con cualidad de ciudad y zonas de urbanización dispersa, fragmentada y segregadora, espacios agrícolas o simplemente expectantes pendientes de ser urbanizables 0 «naturales» más o menos protegidos. Estos territorios suburbanos, lacónicos, que no transmiten sentido alguno, que no tienen cualidad de ciudad, son la imagen de la posmodernidad urbana (Borja, 2012, p. 279-280). 
La ciudad futurista viene a enseñarnos implementaciones tecnológicas y de diseño que podremos adoptar en cualquier tipología de ciudad. En Masdar, más allá de sus controversias, no queda lugar a dudas que su eje fundacional radica en patrones eco-amigables, el ahorro energético y las no emisiones de dióxido de carbono. Pero la ciudad sustentable del futuro podrá ser llevada a cabo siempre que se busque dentro de un equilibrio entre los tipos de eco-ciudad y llevando a la práctica todos los aspectos que la sustentabilidad en sí abarca además de los ecológicos. Los conceptos de Richard Rogers y Jordi Borja ${ }^{17}$ exponen la idea de ciudad sustentable como un conjunto de acciones sustentables relacionadas no sólo con las energías renovables, ahorro energético, y reducción de las emisiones de carbono; sino desde una mirada más integradora, incluyendo la sustentabilidad en las políticas, la participación ciudadana, la igualdad, la no marginalidad, la calidad de los espacios públicos, la sustentabilidad social y financiera; aspirando a una ciudad sustentable en el futuro por medio de un equilibrio nuevo y dinámico entre la sociedad, las ciudades y la naturaleza.

Respecto de la controversia que provoca Masdar, se toman nuevamente las reflexiones de la Dra. Graciela Silvestri (2012):

No es solo que no se pueda hacer Masdar: tal vez no se quiera hacer Masdar (...). Lo grave no es el experimento en sí, del que indudablemente podrán extraerse muchas lecciones tecnológicas, sino la inconsistencia de la opinión pública, y en particular de la corporación arquitectónica, para identificar el tipo de problemas que estas formas de producir "ciudad» suponen. Coloco el término ciudad entre comillas, ya que lo grave en la versión de Masdar es que excluye por definición una esfera pública - que pone en entredicho, entonces, la misma idea de ciudad (p. 200).

Para finalizar, indudablemente se tiende a reflexionar sobre la extraordinaria inversión económica que implica la nueva ciudad, y con ello considerar que seguramente resultaría más conveniente distribuir tales recursos en el mejoramiento de la calidad de vida y las sustentabilidad de ciudades existentes en lugar de construir una nueva. Si bien desde otra mirada, también pueden observarse las ganancias latentes del proyecto derivadas de la innovación e investigaciones en proceso. Las que innegablemente colaborarán en las soluciones destinadas a conservar los recursos disponibles (Oikonomidou, 2012). A su vez, a pesar del aparente fracaso, el proyecto de Masdar City se ha vuelto punto de referencia obligado para cualquier discusión de desarrollo sustentable (Jensen, 2015). La experiencia de Masdar, que incluye tecnología y ambientalismo, nos ha llevado reflexionar de nuevo sobre las ciudades. Sólo el paso del tiempo podrá responder los efectos de la ciudad ex novo en el mundo y la sociedad. 
Notas

1. El presente artículo toma como precedente la Tesis de Grado Urbes futuristas, ¿una ecuación posible? Investigación que busca dar respuesta a cuál será el modelo de ciudad sustentable del futuro haciendo foco en las iniciativas actuales a nivel mundial en pos de buscar una respuesta al crecimiento demográfico previsto y al equilibrio sustentable en todas sus aristas: ecológica, política, económica y social.

2. Graciela Silvestri. Arquitecta y Doctora en Historia. Investigadora del Consejo de Investigaciones Científicas y Técnicas y profesora titular de Teoría de la Arquitectura en la Facultad de Arquitectura y Urbanismo de la Universidad de La Plata.

3. Sheik es el Jeque Árabe Khalifa bin Zayed Al Nahayan, emir hereditario y presidente de los Emiratos Árabes Unidos.

4. EAU: Emiratos Árabes Unidos.

5. Gwanggyo Power Centre. Diseñada por el estudio belga MVRDV, a raíz de un concurso convocado por la empresa coreana Daew0o. No se encuentran noticias de avance del proyecto.

6. New Songdo City. Diseñado por Kohn Perdersen. Avanzada en la construcción al 70\%.

7. Shimizu Try 2004. Su creador es el arquitecto Shimizu. Esta ciudad sería la estructura más grande en la Tierra y la primera ciudad construida en alta mar y en altura. Solo en etapa de proyecto.

8. Dragonfly. Proyecto del arquitecto Vincent Callebaut. Solo en etapa de proyecto.

9. Hydrogenase. Ideada por Vincent Callebaut. Solo en etapa de proyecto.

10. Gulf Cooperation Council. Consejo de Cooperación para los Estados Árabes del Golfo.

11. El Master Plan de Masdar City puede encontrarse en el sitio oficial de Masdar http://www.masdar. ae/en/masdar-city/detail/master-plan. El mismo describe las características y el diseño del proyecto completo.

12. Boris Borman Jensen. Investigador independiente, consultor arquitecto en práctica. Ha publicado y exhibido numerosos proyectos de investigación sobre la globalización, el desarrollo urbano y la teoría de la arquitectura.

13. Richard Rogers. Arquitecto conocido principalmente por obras como el Centre Georges Pompidou en París y el edificio Lloyd's en Londres; y proyectos de urbanismo a gran escala en Shanghái, Berlín y Londres. Medalla de oro del RIBA (Real Instituto de Arquitectos Británicos). Es el presidente del National Tenants Resource Centre y de la Architecture Foundation. En 1998 fue invitado por el primer ministro británico, John Prescott, a presidir la comisión gubernamental de urbanismo encargada de preparar un plan estratégico global para toda Inglaterra.

14. Detroit. Ícono del poderío industrial automotriz y motor en el siglo XX de la economía y el progreso de Estados Unidos, fundada en 1701, vivió un lento declive económico y financiero que devastó su población: de 1.800 .000 habitantes, hoy quedan 685.000 y se declaró en quiebra.

15. El Palacio de Versalles es un edificio que desempeñó las funciones de una residencia real. Su construcción fue ordenada por Luis XIV. Constituye uno de los complejos arquitectónicos monárquicos más importantes de Europa.

16. Los dos siglos de despilfarro de recursos inician desde el desarrollo de la Revolución Industrial, momento en el que comenzó a expandirse la ciudad y la demanda energética a nivel mundial.

17 ordi Borja. Sociólogo, geógrafo y urbanista. Director del área Gestión de la Ciudad y Urbanismo de la Universitat Oberta de Catalunya. Desde la década de los sesenta ha estado vinculado al movimiento ciudadano popular de Barcelona. Ha colaborado como consultor en las principales ciudades de América Latina, Francia y España.

\section{Referencias bibliográficas}

Ascher, F. (2012). La ciudad moderna son los demás. La numerosidad, entre necesidad y azar. En Ciudades, una ecuación imposible. Buenos Aires: Café de las ciudades. 
Borja, J. (2012). El fin de la anticiudad posmodernista y el derecho a la ciudad en las regiones metropolitanas. En M. Belil, J. Borja, \& M. Corti, Ciudades, una ecuación imposible. Buenos Aires: Café de las Ciudades.

Dévora-Isiordia, G. E., González-Enríquez, R., \& Ruiz-Cruz, S. (2013). Evaluación de procesos de desalinización y su desarrollo en México. Tecnología y Ciencias del Agua.

Eco Diario. (2011). Sostenibilidad y arquitectura en los proyectos de ciudades más futuristas. Recuperado de http://ecodiario.eleconomista.es/desarrollo-sostenible/noticias/3014149/04/11/Sostenibilidad-y-arquitectura-en-los-proyectos-de-ciudades-mas-futuristas.html

Fundación Expoterra. (2012). Fundación Expoterra. Recuperado de http://clickworks.com.ar/expoterra_ wp/eco-ciudades-del-futuro-masdar-city/

Galindo, M. (2015). ¿Ciudad inteligente y sostenible?: Masdar City. Recuperado de http://ecoesmas. com/ciudad-inteligente-masdar-city/

Goitia, A. (2013). La ciudad del mañana. Masdar City - Abu Dhabi. En A. Goitia, Arquitectos Pritzker, Norman Foster. Buenos Aires: ARQ Clarín.

Hurtado, J. F. (2013). Urbes Futuristas. In, 51-60.

Jensen, B. B. (2015). Masdar City: A Critical Retrospection. Recuperado de https://urbannext.net/masdar-city-a-critical-retrospection-2/

Joss, S. (2010). Eco-Cities - A Global Survey 2009. Part A: Eco-City Profiles. Westminster: University of Westminster.

Kingsley, P. (2013). Masdar: the shifting goalposts of Abu Dhabi's ambitious eco-city. Recuperado de http://www.wired.co.uk/magazine/archive/2013/12/features/reality-hits-masdar

Lancellotti Pérez, G. (2010). Financiamiento de Proyectos Urbano-Ecológicos mediante intercambio de bonos de carbono. Recuperado de http://www.redalyc.org/html/198/19817730004/index.html

Le Corbusier. (1924). La ciudad del futuro. París: Infinito.

Mandel, J. (2010). 'Green City' Builders Facing Technological, Financial Hurdles. New York Times.

Oikonomidou, C. (2012). Re-Conecta. Recuperado de http://www.reconecta.com/masdar-\%C2\%BFuna-ciudad-realmente-sustentable/

Rivas Ecópolis. (2008). Proyecto Rivas Ecópolis. Sobre el desarrollo de Rivas Vaciamadrid como ciudad sostenible. (M. Spotti, Ed.) Madrid: Rivas Vaciamadrid.

Rogers, R. (2003). Ciudades para un pequeño planeta. Barcelona: Gustavo Gilli.

Rondón, L.A. (2009). El ambiente y el desarrollo sustentable en la ciudad latinoamericana. Investigación y Desarrollo, 268-287.

Silvestri, G. (2012). Las múltiples disoluciones de la arquitectura. En M. Belil, J. Borja, \& M. Corti, Ciudades, una ecuación imposible. Buenos Aires: Café de las Ciudades.

Yujnovsky, 0. (1971). La estructura interna de la ciudad. El caso latinoamericano. Buenos Aires: SIAP.

Zamler, D. (2013). Urbes futuristas, una ecuación posible? No publicado. Buenos Aires.

\section{Figuras}

Figura 1. Foster \& Partners. (2008). Master Plan Masdar. Recuperado de http://www.fosterandpartners. com/es/projects/masdar-development/

Figura 2. Ibídem. Calle interior. Recuperado de http://www.fosterandpartners.com/es/projects/masdar-development/

Figura 3. Ibídem. Espacio público semicubierto. Recuperado de http://www.fosterandpartners.com/es/ projects/masdar-development/

Figura 4. Masdar, a Mubadala Company (s.f). Servicio de taxis subterráneo. Recuperado de http://www. masdar.ae/en/masdar-city/detail/masdar-city-at-a-glance

Figura 5. About Masdar clean energy. (s.f). Planta de paneles solares. Recuperado de http://www.masdar. ae/en/energy/about-masdar-clean-energy 
Figura 6. Antony, T.(s.f). Shams 1. Planta de energía solar. Recuperado de http://www.wired.co.uk/magazine/archive/2013/12/features/reality-hits-masdar

Figura 7. Masdar city. (s.f). Centro de estudios académicos. Recuperado de http://www.masdar.ae/assets/ downloads/content/270/masdar_city_brochure.pdf

Figura 8. Masdar, a Mubadala Company. (s.f). Laboratorios. Recuperado de http://www.masdar.ae/assets/downloads/content/3582/factsheet-masdar_city.pdf

Figura 9. Tuexperto (2009). Gwanggyo Power Centre. Recuperado de http://www.tuexperto. com/2009/01/31/gwanggyo-power-centre-una-ciudad-ecologica-en-corea-del-sur/

Figura 10. Datuopinion (s.f). New Songdo City Recuperado de http://www.datuopinion.com/new-songdo-city

Figura 11. Ecodiario (2011). Shimizu Try 2004. Recuperado de http://ecodiario.eleconomista.es/desarroIlo-sostenible/noticias/3014149/04/11/

Figura 12. Vincet Callebaut Architectures (s.f). Dragonfly. Recuperado de http://vincent.callebaut.org/ page1-img-dragonfly.html

Figura 13. Callebaut, V. (2015). Hydrogenase. Recuperado de http://www.dezeen.com/2010/05/07/hydrogenase-by-vincent-callebaut/

Figura 14. Foster \& Partners. (2008). Calle interna. Recuperado de http://www.fosterandpartners.com/es/ projects/masdar-development/

Figura 15. Ibídem. Calle interna. Recuperado de http://www.fosterandpartners.com/es/projects/masdar-development/

Figura 16. Masdar City: A Critical Retrospection (s.f). Ingreso a Masdar. Recuperado de https://urbannext. net/masdar-city-a-critical-retrospection-2/

Figura 17. Ibídem. Estado actual Masdar. Recuperado de https://urbannext.net/masdar-city-a-critical-retrospection-2/

Figura 18. Foster \& Partners. (2008). Masdar bajo construcción. Recuperado de http://www.fosterandpartners.com/es/projects/masdar-development/

Figura 19. Antony, T. (s.f). Masdar actualmente. Recuperado de http://www.wired.co.uk/magazine/archive/2013/12/features/reality-hits-masdar 